\title{
HYPHOMYCETES COM CONIDIOMA DOS TIPOS ESPORODÓQUIO E SINEMA ASSOCIADOS A FOLHAS DE CEDRELA FISSILIS (MELIACEAE), EM MARINGÁ, PR, BRASIL ${ }^{1}$
}

\author{
Luís Fernando Pascholati Gusmão, \\ Rosely Ana Piccolo Grandi
}

Recebido em 10/6/97. Aceito em 30/10/97

\begin{abstract}
RESUMO - (Hyphomycetes com conidioma dos tipos esporodóquio e sinema associados a folhas de Cedrela fissilis (Meliaceae), em Maringá, PR, Brasil). Folhas vivas e em decomposição de Cedrela fissilis Vell. foram coletadas, de janeiro a novembro de 1993, no Horto Florestal "Dr. Luiz Teixeira Mendes", Municipio de Maringá, PR, Brasil ( $\left.23^{\circ} 25^{\prime} \mathrm{S}, 51^{\circ} 25^{\prime} \mathrm{W}\right)$, com a finalidade de isolar Hyphomycetes. As amostras foliares passaram pela técnica de lavagem vigorosa com água destilada esterilizada e plaqueamento em câmaras-úmidas. Foram isoladas três espécies com conidioma do tipo esporodóquio, Epicoccum nigrum Link, Volutella minima Höhn. e Wiesneriomyces laurinus (Tassi) Kirk, e três com conidioma do tipo sinema, Menisporopsis theobromae S. Hughes, Thozetella cristata Piroz. \& Hodges e T. cubensis Castañeda \& Arnold. Todas as espécies ocorreram no folhedo sendo predominantes $M$. theobromae, $T$. cristata e $W$. laurinus. Em folhas vivas foram isoladas apenas $E$. nigrum e $V$. minima. São apresentadas, para cada espécie, descrição, distribuição geográfica, comentários e ilustrações. Todas as espécies estão sendo citadas pela primeira vez para o Estado do Paraná; $T$. cubensis é referida pela primeira vez para o Brasil.
\end{abstract}

Palavras-chave: Epicoccum, Menisporopsis, Thozetella, Volutella, Wiesneriomyces

\begin{abstract}
Hyphomycetes with sporodochial and synnematous conidiomata associated with leaves of Cedrela fissilis (Meliaceae) in Maringá, PR, Brazil). With the aim to study Hyphomycetes, leaves of Cedrela fissilis Vell. were collected from January to November of 1993, in the "Horto Florestal Dr. Luiz Teixeira Mendes", Municipality of Maringá, PR, Brazil ( $\left.23^{\circ} 25^{\prime} \mathrm{S}, 51^{\circ} 25^{\prime} \mathrm{W}\right)$. The leaves were prepared by washing with serial changes of sterile distilled water and incubated in moist chambers. Three species with sporodochial conidiomata, Epicoccum nigrum Link, Volutella minima Höhn. and Wiesneriomyces laurinus (Tassi) Kirk and three with synnematous type, Menisporopsis theobromae S. Hughes, Thozetella cristata Piroz. \& Hodges and T. cubensis Castañeda \& Arnold were isolated. All these species colonize $C$. fissilis leaf litter with $M$. theobromae, $T$. cristata, and $W$. laurinus being the most commonly found. From living leaves of $C$. fissilis only $E$. nigrum and $V$. minima were isolated. Descriptions, geographical distributions, coments, and illustrations are included for each species. All these species are cited for the first time to Paraná State. T. cubensis is registered for the first time to Brazil.
\end{abstract}

Key words: Epicoccum, Menisporopsis, Thozetella, Volutella, Wiesneriomyces

\footnotetext{
'Trabalho apresentado no XLVII Congresso Nacional de Botânica, Nova Friburgo, RJ

${ }^{2}$ Instituto de Botânica, C.P. 4005, CEP 01061-970, São Paulo, SP, Brasil

${ }^{3}$ Bolsista convênio $\mathrm{CNPq} /$ Universidade Estadual de Maringá

${ }^{4}$ Bolsa de Pesquisa CNPq
} 


\section{Introdução}

Os fungos são conhecidos como decompositores de material vegetal contribuindo sobremaneira para a ciclagem de nutrientes nos ecossistemas (Cooke \& Rayner 1984). Dentre esses, os Hyphomycetes destacam-se na decomposição da serapilheira, podendo também ser encontrados associados a folhas vivas de vegetais (Hudson 1968; Dix \& Webster 1995). Neste último aspecto, muitos Hyphomycetes podem ser parasitas, patógenos latentes, ou ter efeito benéfico sobre seus hospedeiros (Gams 1992).

Os Hyphomycetes são comumente isolados da natureza na sua fase assexual, denominada anamorfa. No entanto, podem apresentar a fase sexual, conhecida como teleomorfa, que é representada principalmente pelos Ascomycotina (Hawksworth et al. 1995). A fase anamorfa caracteriza-se pela presença de estruturas de reprodução assexuada, sendo então os fungos identificados pelos conídios e conidióforos que se dispõem de modos peculiares.

Os conídios têm como principais funções a dispersão e a perpetuação da espécie. A grande variedade de formas é de importância taxonômica (Carmichael et al. 1980) e, muitas vezes, pode-se correlacioná-las com o habitat e a maneira de dispersão (Dix \& Webster 1995).

Os conidióforos podem ou não estar presentes nos Hyphomycetes. Quando presentes, podem ser distintos das hifas vegetativas, portando as células conidiogênicas. Os conidióforos podem ser livres ou apresentar vários tipos de organização, denominado conidioma, dentre os quais o do tipo esporodóquio e o do tipo sinema (Hawksworth et al. 1995).

O conidioma do tipo esporodóquio é caracterizado pela presença de uma massa de conídios sobre um aglomerado de conidióforos curtos, formando um pseudoparênquima (Hawksworth et al. 1995). O conidioma do tipo sinema é definido como um grupo de conidióforos compactados, eretos, relativamente longos e, muitas vezes, fundidos, dando origem aos conídios no ápice e/ou nas laterais (Seifert 1985). Ambos os tipos de conidioma podem apresentar estruturas estéreis associadas, tais como setas, ou células com denominações especiais.

Embora se tenha conhecimento razoável dos Hyphomycetes em termos mundiais, no Brasil os estudos desse grupo ainda são poucos, principalmente no que diz respeito ao levantamento das espécies associadas a substratos vegetais específicos na natureza (Grandi 1993). No entanto, existem relatos para folhas em decomposição de Cedrela fissilis Vell., publicados para os Estados de São Paulo (Grandi et al. 1994; 1995) e do Paraná (Grandi \& Gusmão 1995; Gusmão et al. 1995; Gusmão \& Grandi 1996).

O presente trabalho tem como objetivos o levantamento, a caracterização e o fornecimento de dados sobre a distribuição geográfica de Hyphomycetes com conidióforos agrupados que ocorrem no folhedo e sobre folhas vivas de Cedrela fissilis (cedro), espécie arbórea presente nas matas remanescentes de planalto, no Estado do Paraná.

\section{Material e métodos}

Folhas vivas e em decomposição de Cedrela fissilis foram coletadas de exemplares escolhidos dentro do Horto Florestal "Dr. Luiz Teixeira Mendes", de propriedade da 
Companhia Melhoramentos Norte do Paraná, Município de Maringá, PR ( $23^{\circ} 25^{\prime} \mathrm{S}$, $51^{\circ} 25$ 'W). A área em questão tem altitude média de $556 \mathrm{~m}$ e ocupa aproximadamente 37ha. A vegetação da região é caracterizada como mata tropical subcaducifólia de planalto (EMBRAPA/IAPAR 1984).

Foram coletadas bimestralmente três amostras de folhedo, de janeiro a novembro de 1993. Nos meses de março e setembro do mesmo ano foram realizadas coletas de folhas vivas, utilizando-se apenas as que se apresentavam maduras e em bom estado. Cada amostra constituiu-se de 20 folhas, as quais passaram pela técnica de lavagem vigorosa com água destilada esterilizada (Harley \& Waid 1955; Grandi 1990). Após a lavagem, as folhas foram seccionadas em fragmentos com cerca de $5 \mathrm{~mm}$ de comprimento e aproximadamente 100 fragmentos foliares foram colocados em câmaras-úmidas, as quais foram deixadas à temperatura ambiente $\left(18-22^{\circ} \mathrm{C}\right)$ e mantidas úmidas durante 45 dias, período de isolamento dos fungos.

Através de microscópio estereoscópico e com auxílio de agulhas histológicas, os conidiomas foram removidos do substrato e colocados em lâminas com meio de montagem PVL (resina de álcool polivinílico e lactofenol), segundo Trappe \& Schenck (1982), confeccionando-se lâminas permanentes para observação microscópica. A identificação baseou-se em análises morfo-micrométricas convencionais. Após identificação, os espécimes foram selecionados e os representativos incorporados ao Herbário Científico "Maria Eneyda P. Kauffmann Fidalgo" (SP), do Instituto de Botânica, São Paulo.

\section{Resultados e discussão}

Chave para os gêneros encontrados

1. Conidioma do tipo esporodóquio

2. Setas ausentes; conídios multicelulares e castanhos.

1. Epicoccum

2. Setas presentes; conídios unicelulares e hialinos, unidos em massa mucilaginosa

3. Setas hialinas; conídios solitários

4. Volutella

3. Setas castanho-escuras; conídios produzidos em cadeias com 5-10 elementos

5.Wiesneriomyces

1. Conidioma do tipo sinema

4. Setas presentes; ausência de células estéreis

4. Setas ausentes; presença de células estéreis ("microawns")

2. Menisporopsis

3. Thozetella

\section{Epicoccum Link}

Esporodóquios castanhos ou negros, pulverulentos, espalhados ou agregados na superfície do substrato; conidióforos curtos, pouco diferenciados, sem ramificações ou ocasionalmente ramificados, retos ou recurvados, hialinos a castanho-claros, lisos ou verrucosos; células conidiogênicas monoblásticas, integradas, terminais, determinadas, cilíndricas; conídios solitários, blásticos, muriformes, esféricos, subesféricos ou piriformes, conspicuamente verrucosos; castanho-amarelados a castanho-escuros, com uma célula basal mais clara. 
Espécie-tipo: Epicoccum nigrum Link

Gênero com ampla distribuição e fase teleomorfa desconhecida (Hawksworth et al. 1995). Após o trabalho de revisão realizado por Schol-Schwarz (1959), apenas duas espécies foram aceitas, E. nigrum e E. andropogonis (Ces.) Schol-Schwarz, com o gênero Cerebella sendo estabelecido como sinônimo de Epicoccum. No entanto, Ellis (1971) considera-os gêneros distintos. Recentemente foram acrescentadas mais duas espécies ao gênero, E. nipponicum e E. yunnanense, descritas por Matsushima (1995).

Epicoccum nigrum Link, Mag. Ges. naturf. Fr. Berl. 7: 32. 1815.

Fig. 1-3.

Esporodóquios castanho-escuros, coloração apresentada pelo aglomerado de conídios; conidióforos curtos, não ramificados, retos ou flexuosos, lisos, castanhoclaros; conídios solitários, subesféricos, muriformes, verrucosos, castanhos a castanhoescuros, 17,7-37,3 $\mu \mathrm{m}$ diâm.

Material examinado: BRASIL. Paraná: Maringá, 06/IX/93, sobre folhas vivas de Cedrela fissilis, Gusmão 025 (SP251217).

Distribuição geográfica: cosmopolita (Ellis 1971; Grandi 1993).

Epicoccum nigrum é caracterizada pelos conídios muriformes e verrucosos (Ellis 1971). É uma espécie muito comum, ocorrendo no solo, sobre vegetais vivos ou mortos e outros substratos; sua distribuição, no Brasil, foi dada por Grandi (1985). A espécie foi isolada em três oportunidades: março, sobre folhas vivas; julho, no folhedo e setembro, sobre folhas vivas e em decomposição.

\section{Menisporopsis S. Hughes}

Sinemas eretos, castanho-claros a escuros; setas eretas, não ramificadas, septadas, lisas, ápice arredondado ou pontiagudo, castanhas, base envolvida por conidióforos agregados; conidióforos eretos ou flexuosos, não ramificados, septados, castanhoclaros; células conidiogênicas tipo fiálide, integradas, terminais, cilíndricas; conídios lunados ou fusiformes, 0-1-septados, hialinos, comumente com uma ou mais sétulas nas extremidades, de tamanhos iguais ou não, unidos por mucilagem.

Espécie-tipo: Menisporopsis theobromae S. Hughes

Hawksworth et al. (1995) relatam que o gênero possui apenas duas espécies, com distribuição aparentemente restrita (África e Nova Zelândia) e fase teleomorfa desconhecida; no entanto, a consulta a literatura especializada para o táxon revelou que seis espécies compõem o gênero atualmente.

Menisporopsis theobromae S. Hughes, Mycol. Pap. 48: 59. 1952.

Fig. 4-5. 
Sinema composto de uma seta central proeminente, cilíndrica, não ramificada, septada, castanha, 148,4-226,6x4,7-6,7 $\mu \mathrm{m}, 2,7-3,2 \mu \mathrm{m}$ larg. no ápice; conidióforos arranjados em fascículos paralelos ascendentes, septados, castanho-claros, 45,6-85,7x8,0-29,1 $\mu \mathrm{m}$ larg. na base; células conidiogênicas integradas, terminais, fialídicas, castanho-claras a hialinas, 2,7-4,6 $\mu \mathrm{m}$ larg.; conídios agregados em muco, fusiformes ou ligeiramente curvos, arredondados nas extremidades, unicelulares, lisos, hialinos, com uma sétula em cada extremidade, $12,4-16,3 \times 1,9-3,1 \mu \mathrm{m}$; sétulas filiformes, finas, hialinas, 5,6-9,0 $\mu \mathrm{m}$ compr.

Material examinado: BRASIL. Paraná: Maringá, 05/III/93, no folhedo de Cedrela fissilis, Gusmão 026 (SP251218 ); 05/III/93, no folhedo de Cedrela fissilis, Gusmão 027 (SP251219).

Distribuição geográfica: Brasil (Batista et al. 1965); Taiwan (Matsushima 1980); Peru (Matsushima 1993); Austrália, Costa do Marfim, Cuba, Gana, Guiana Francesa, Japão, México, Nova Zelândia, Papua-Nova Guiné (Abarca 1994).

Menisporopsis theobromae é a espécie mais comum do gênero, sendo caracterizada pela presença de uma seta envolta por conidióforos fasciculados e conídios com uma sétula em cada extremidade (Hughes 1952; Ellis 1971; Abarca 1994). O número de sétulas nos conídios é de importância taxonômica (Rao \& Hoog 1986; Mouchacca 1990), bem como a posição das células conidiogênicas (Pirozynski 1972). A espécie concentra-se nas regiões tropicais e já foi referida para o Estado do Amapá por Batista et al. (1965). A espécie só ocorreu no folhedo, em quase todos os meses de coleta, à exceção de julho e novembro.

\section{Thozetella Kuntze}

Sinemas eretos, com ou sem zonas de crescimento; conidióforos fortemente agregados, castanho-claros, septados, lisos, ramificados, com uma célula conidiogênica no ápice; células conidiogênicas tipo fiálide, hialinas, terminais, cilíndricas, lisas, com ou sem colarete; conídios lunados, unicelulares, lisos, hialinos, com sétulas filiformes nas extremidades; células estéreis ("microawns") produzidas junto com os conídios, sigmóides, lunadas ou em L, hialinas e refringentes; conídios e células estéreis agrupados em mucilagem de coloração branca, no ápice do conidioma.

Espécie-tipo: Thozetella nivea (Berk. \& Muell.) Kuntze

Gênero referido para regiões temperadas e tropicais com fase teleomorfa desconhecida (Hawksworth et al. 1995). Sutton \& Cole (1983), analisando algumas espécies de Thozetella descritas à época, destacaram que o tipo de conidioma é caráter secundário para a taxonomia do gênero, podendo apresentar estruturas intermediárias entre esporodóquio e sinema, tanto em substratos naturais como em cultura. Os espécimes obtidos no presente estudo exibiram sinemas de acordo com o conceito de Seifert (1985). Oito espécies constituem o gênero, sendo duas verificadas no presente estudo. 
Chave para as espécies de Thozetella

1. Células estéreis ("microawns") sigmóides, $23,0-70,0 \mu \mathrm{m}$ compr...3.1.T. cristata

1. Células estéreis ("microawns") em L, longas e afiladas, $46,0-123,0 \mu \mathrm{m}$ compr.

3.2. T. cubensis

Thozetella cristata Pirozynski \& Hodges, Can. J. Bot. 51: 168. 1973. Fig. 6-8.

Sinema ereto, hialino, apresentando uma zona de crescimento castanho-clara, até $250 \mu \mathrm{m}$ compr.; conidióforos densamente unidos; células estéreis ("microawns") sigmóides, lisas, hialinas, 23,4-68,9×2,1-2,8 $\mu \mathrm{m}$; conídios lunados, com uma sétula em cada extremidade, unicelulares, lisos, hialinos, formando uma massa ovóide a subglobosa, 9,5-15,1×2,3-3,4 $\mu \mathrm{m}$; sétulas filiformes, hialinas, 5,1-6,1 $\mu \mathrm{m}$ compr.

Material examinado: BRASIL. Paraná: Maringá, 05/V/93, no folhedo de Cedrela fissilis, Gusmão 028 (SP251220).

Distribuição geográfica: Estados Unidos da América (Pirozynski \& Hodges 1973); Itália (Lunghini \& Quadraccia 1990); Brasil e Japão (Grandi 1993; Grandi et al. 1995).

A presença e a morfologia das células estéreis ("microawns") são características taxonômicas marcantes do gênero Thozetella e de suma importância para identificação das espécies (Sutton \& Cole 1983). T. cristata apresenta zonas de crescimento no conidioma, característica só relatada, até o momento, para essa espécie (Pirozynski \& Hodges 1973; Grandi 1993). A zona de crescimento representa a área onde ocorreu proliferação sincronizada dos conidióforos. A espécie foi relatada pela primeira vez para o Brasil por Grandi (1993) tendo ocorrido, no presente estudo, apenas no folhedo, em quase todos os meses de coleta, à exceção de setembro e novembro.

Thozetella cubensis Castañeda \& Arnold, Rev. Jard. Bot. Nac. 6: 511985. Fig. 9-10.

Sinema ereto, hialino; conidióforos densamente unidos; células estéreis ("microawns") comumente em forma de L, ápice longo e fino, lisas, hialinas, 46,1122,2 × 2,2-3,0 $\mu$ m; conídios falcados a lunados, com uma sétula em cada extremidade, unicelulares, lisos, hialinos, formando uma massa ovóide, 12,6-16,1×2,4-2,8 $\mu \mathrm{m}$; sétulas filiformes, hialinas, 5,2-9,0 $\mu \mathrm{m}$ compr.

Material examinado: BRASIL. Paraná: Maringá, 05/III/93. no folhedo de Cedrela fissilis, Gusmão 030 (SP251221).

Distribuição geográfica: Cuba (Castañeda \& Arnold 1985).

Thozetella cubensis foi descrita por Castañeda \& Arnold (1985) possuindo conidioma do tipo esporodóquio. No entanto, no presente estudo, considerou-se o conidioma do tipo sinema, em função do material examinado, e de acordo com a 

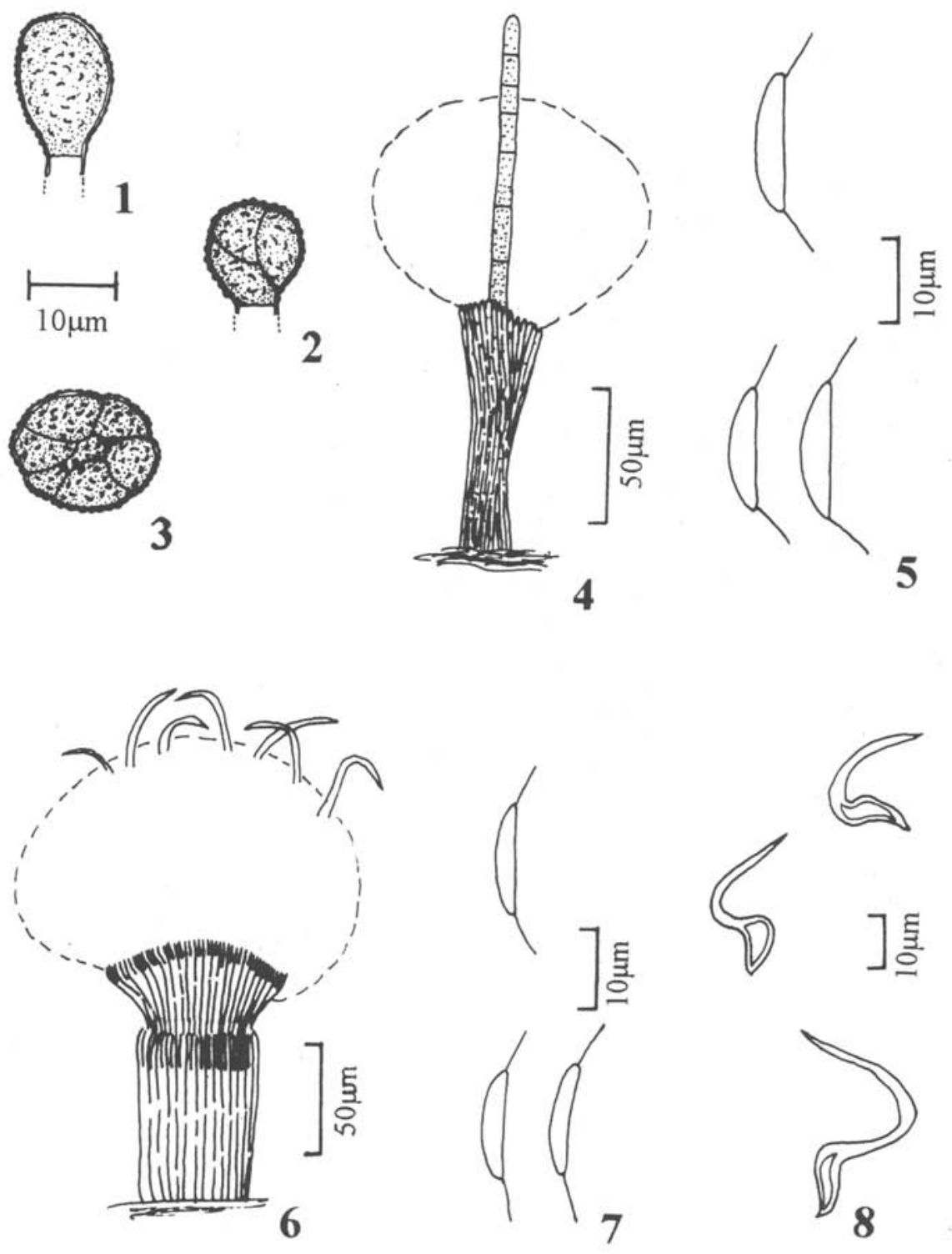

Figuras 1-3. Epicoccum nigrum Link. 1-2. Conidios jovens. 3. Conidio maduro. Figuras 4-5. Menisporopsis theobromae S. Hughes. 4. Aspecto geral do sinema. 5. Conidios. Figuras 6-8. Thozetella cristata Pirozynski \& Hodges. 6. Aspecto geral do sinema. 7. Conídios. 8. Células estéreis ("microawns"). 
variação exibida em Thozetella (Seifert \& Okada 1990). Poucos espécimes foram isolados e os sinemas não puderam ser medidos e ilustrados devido à preparação. Contudo, a espécie pôde ser identificada pois é a única do gênero que possui "microawns" com tal morfologia e, assim, ser referida pela primeira vez para o Brasil. A espécie ocorreu apenas no folhedo, no mês de março.

\section{Volutella Fries}

Esporodóquios sésseis ou com pequenos pedúnculos, hialinos ou de coloração clara e brilhante, circundados por setas, com massa conidial agregada por mucilagem na parte central; setas pontiagudas, septadas, hialinas, lisas; conidióforos fortemente agregados, simples ou ramificados; células conidiogênicas tipo fiálide, no ápice dos conidióforos; conídios unicelulares, pequenos, ovais, elípticos ou cilíndricos, hialinos, produzidos um a um sucessivamente, porém unidos em massa mucilaginosa..

Espécie-tipo: Volutella ciliata Alb. \& Schw.:Fr.

Gênero com ampla distribuição e fase teleomorfa incluida nos táxons Nectria ou Pseudonectria (Ascomycotina); cerca de 120 espécies foram publicadas, porém apenas 20 espécies são aceitas até o momento (Carmichael et al. 1980; Domsch et al. 1980; Samuels \& Dumont 1982; Hawksworth et al. 1995), faltando revisão criteriosa para o gênero.

Volutella minima Höhnel, Sitzungsber. Kiserl. Akad. Wiss., Math.-Naturwiss. Abt I, 118: 1543.1909.

Fig. 11-12.

Esporodóquios sésseis ou pedunculados, hialinos; setas retas, pontiagudas, pouco septadas, lisas, hialinas, $161,1-364,9 \times 2,4-8,5 \mu \mathrm{m}$; conídios unicelulares, cilíndricos com extremidades arredondadas, hialinos, agrupados por mucilagem hialina a amarela, $3,8-6,8 \times 1,0-2,0 \mu \mathrm{m}$.

Material examinado: BRASIL. Paraná: Maringá, 05/III/93, sobre folhas vivas de Cedrela fissilis, Gusmão 031 (SP251222); 05/III/93, Gusmão 032 (SP251223).

Distribuição geográfica: Colômbia, Estados Unidos da América, Java, Nova Zelândia, Panamá, (Samuels \& Dumont 1982); Brasil, Índia, Reino Unido (Pfenning 1993); Peru (Matsushima 1993).

A espécie mais comum do gênero é Volutella ciliata, que difere de V. minima na forma e dimensões dos conídios (Gamundi et al. 1979; Pfenning 1993). V. comata Ellis, V. longipila A. L. Smith \& Ramsbotton e V. ramkumarii Sarbhoy são consideradas sinônimos de V. minima por Pfenning (1993). No entanto, Matsushima $(1989,1993)$ indica como sinônimos apenas $V$. longipila e V. ramkumarii, considerando $V$. minima outro táxon. Nectria consors (Ellis \& Everhart) Seaver é o estádio teleomorfo de $V$. minima (Samuels \& Dumont 1982). Para o Brasil, a espécie foi relatada por Pfenning 
(1993). Neste estudo, a espécie ocorreu em folhas vivas e em decomposição, apenas no mês de março.

\section{Wiesneriomyces Koorders}

Esporodóquios castanho-claros, providos de setas, com massa conidial agregada por mucilagem na parte central; setas pontiagudas, septadas, não ramificadas, lisas, castanhas a castanho-escuras, recurvadas em direção ao centro do esporodóquio ou eretas; conidióforos fortemente unidos, ramificados no ápice, retos ou recurvados, lisos, hialinos a castanho-claros; células conidiogênicas poliblásticas, determinadas, clavadas ou cilíndricas, com 2-3 protuberâncias onde se prendem os conídios; conídios unicelulares, lisos, hialinos, produzidos em cadeias; conídios das extremidades das cadeias cônicos, e os intermediários cilíndricos.

\section{Espécie-tipo: W. laurinus (Tassi) P.M. Kirk}

Gênero com ampla distribuição e fase teleomorfa desconhecida (Hawksworth et al. 1995). Até 1988, apenas Wiesneriomyces laurinus era conhecido dentro do gênero, quando foi descrito $W$. conjunctosporus, por Kuthubutheen \& Nawawi (1988). Atualmente, apenas essas duas espécies fazem parte do gênero.

Wiesneriomyces laurinus (Tassi) P. M. Kirk, Trans. Br. Mycol. Soc. 82: 748. 1984. Fig. 13-14.

Esporodóquios sésseis ou pedunculados, castanhos; setas pontiagudas, septadas, lisas, recurvadas para o interior do esporodóquio, castanhas a castanho-escuras, 163,3300,8x4,6-8,5 $\mu \mathrm{m}$; conidióforos e células conidiogênicas fortemente unidos, dificeis de serem observados; conídios unicelulares, cilíndricos e cuneiformes, lisos, hialinos,

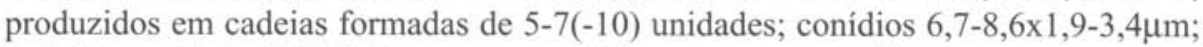
cadeias conidiais $35,9-53,3 \mu \mathrm{m}$ compr., unidos em massa mucilaginosa.

Material examinado: BRASIL. Paraná: Maringá, 05/V/93, no folhedo de Cedrela fissilis, Gusmão 033 (SP251224).

Distribuição geográfica: cosmopolita.

Wiesmeriomyces laurinus é caracterizado pelas setas vigorosas e recurvadas para o centro do esporodóquio e pelos conídios dispostos em cadeias (Maniotis \& Strain 1968; Ellis 1971). Há pouco tempo atrás a espécie era conhecida como $W$. javanicus; porém, analisando o holotipo de Volutellaria laurina Tassi, Kirk (1984) concluiu ser este o nome mais antigo para o táxon em questão, e propôs uma nova combinação, $W$. laurinus (Tassi) P.M. Kirk. Nesse mesmo trabalho são apresentados três sinônimos nomenclaturais: Volutellaria laurina Tassi, Chaetopeltis laurina (Tassi) Sacc., Tassia laurina (Tassi) H. \& P. Sydow e um taxonômico: Wiesneriomyces javanicus Koorders. Kirk (1981) cita material depositado no herbário IMI (Reino Unido) proveniente do Brasil. A espécie ocorreu somente no folhedo, nos meses de março, maio e setembro. 

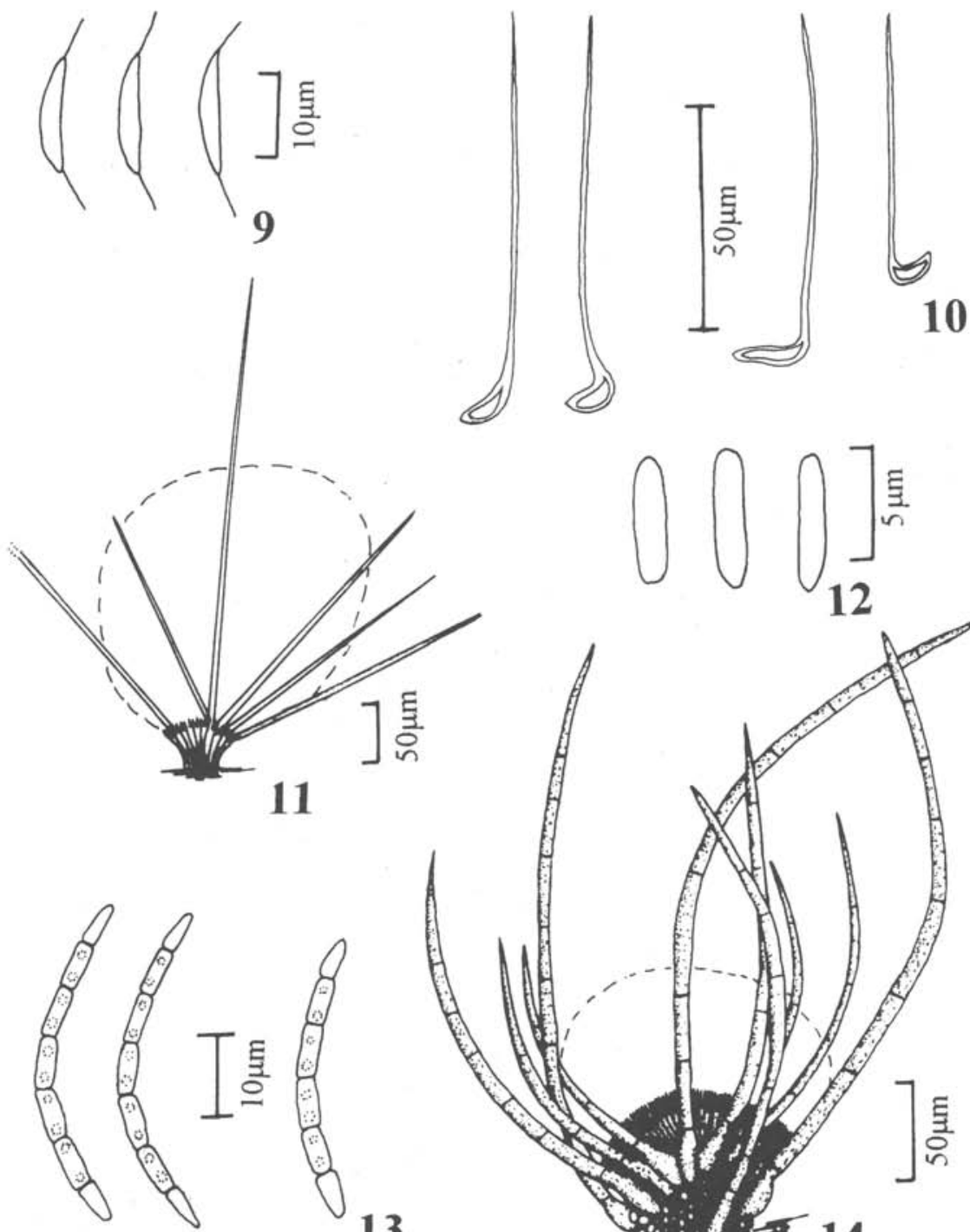

12

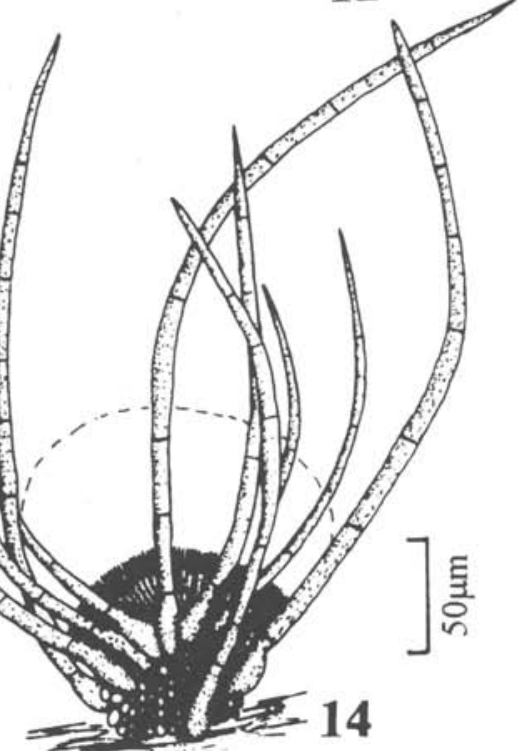

Figuras 9-10. Thozetella cubensis Castañeda \& Arnold. 9. Conídios. 10. Células estéreis ("microawns"). Figuras 11-12. Volutella minima Höhnel. 11. Aspecto geral do esporodóquio. 12. Conídios. Figuras 13-14. Wiesneriomyces laurinus (Tassi) P. M. Kirk. 13. Conidios em cadeia. 14. Aspecto geral do esporodóquio. 


\section{Referências bibliográficas}

Abarca, G.H. 1994. Hifomicetos dematiaceos en bosque mesofilo de montaña. Registros nuevos para Mexico. Acta Botanica Mexicana 27: 15-32.

Batista, A.C.; Falcão, R.G.; Maciel, M.J.P. \& Maia, H.S. 1965. Alguns Dematiaceae amerospóricos. Publicações do Instituto de Micologia, Universidade Federal do Recife 447: 1-35.

Carmichael, J.W.; Kendrick, B.; Conners, I.L. \& Sigler, L. 1980. Genera of Hyphomycetes. Edmonton. The University of Alberta Press.

Castañeda Ruiz, R.F. \& Arnold, G.R.W. 1985. Deuteromycotina de Cuba. I. Hyphomycetes. Revista del Jardín Botánico Nacional 6(1): 47-67.

Cooke, R.C. \& Rayner, A.D.M. 1984. Ecology of Saprotrophic Fungi. New York. Longman.

Dix, N.J. \& Webster, J. 1995. Fungal Ecology. London. Chapman \& Hall.

Domsch, K.H.; Gams, W. \& Anderson, T. 1980. Compendium of Soil Fungi. London. Academic Press.

Ellis, M.B. 1971. Dematiaceous Hyphomycetes. London. Commonwealth Mycological Institute.

EMBRAPA/IAPAR 1984. Levantamento e reconhecimento dos solos do Estado do Paraná. Londrina: Empresa Brasileira de Pesquisa Agropecuária/ Instituto Agronômico do Paraná Vol. II.

Gams, W. 1992. The analysis of communities of saprophytic microfungi with special reference to soil fungi. Pp. 183-223.In W., Winterhoff (Ed.), Fungi in Vegetation Science. London. Kluwer Academic Publishers,

Gamundi, I.J.; Arambarri, A.M. \& Bucsinszky, A.M. 1979. Micoflora de la hojarasca de Nothofagus dombeyi, II. Darwiniana 22 (1-3): 189-216.

Grandi, R.A.P. 1985. Hyphomycetes do Estado de São Paulo. 1. Espécies do cerrado da Reserva Biológica de Moji-Guaçu. Rickia 12: 125-145.

Grandi, R.A.P. 1990. Hyphomycetes decompositores 1. Espécies associadas às raizes de Calathea stromata (horticultural). Revista Brasileira de Biologia 50(1): 123-132.

Grandi, R.A.P. 1993. Hyphomycetes associados a folhas em decomposição de Alchornea triplinervia (Spreng.) M. Arg. e Euterpe edulis Mart. São Paulo. Universidade de São Paulo. Tese de Doutorado.

Grandi, R.A.P.; Delitti, W.B.C. \& Grandi, A.C. 1994. Comparação de Hyphomycetes isolados de folhas em decomposição de Cedrela fissilis Vell., submetidas a tratamento com naftalina e nutrientes. Anais do III Simpósio de Ecossistemas da Costa Brasileira: subsídios a um gerenciamento ambiental. São Paulo. Publicação ACIESP 87(2): 114-117.

Grandi, R.A.P.; Grandi,A.C. \& Delitti, W.B.C. 1995. Hyphomycetes sobre folhas em decomposição de Cedrela fissilis Vell. Hoehnea 22(1/2): 27-37.

Grandi, R.A.P. \& Gusmão, L.F.P. 1995. Espécies de Gyrothrix (Hyphomycetes) no folhedo de Cedrela fissilis Vell., em Maringá, PR, Brasil. Hoehnea 22(1/2): 191-196.

Gusmão, L.F.P. \& Grandi, R.A.P. 1996. Espécies do grupo Beltrania (Hyphomycetes) associadas a folhas de Cedrela fissilis Vell. (Meliaceae), em Maringá, PR, Brasil. Hoehnea 23(1): 91-102.

Gusmão, L.F.P.; Schwan-Estrada, K.R.F. \& Santos, V.D. 1995. Fungos associados à decomposição de folhas de Aspidosperma polyneuron Mull. Arg. e de Cedrela fissilis Vell. Anais do $9^{\circ}$ Congresso da Sociedade Botânica de São Paulo. Ilha Solteira, p. 61-65.

Harley, J.L. \& Waid, J.S. 1955. A method of studing active mycelia on living roots and other surfaces in the soil. Transactions of the British Mycological Society 38: 104-118.

Hawksworth, D.L.; Kirk, P.M.; Sutton, B.C. \& Pegler, D.N. 1995. Ainsworth \& Bisby's Dictionary of the Fungi. 8th ed. Wallingford. $\mathrm{CAB}$ International.

Hudson, H.J. 1968. The ecology of fungi on plant remains above the soil. New Phytologist 67: 837-874.

Hughes, S.J. 1952. Fungi from the Gold Coast. I. Mycological Papers 48: 1-91.

Kirk, P.M. 1981. New or interesting microfungi III. A preliminary account of microfungi colonizing Laurus nobilis leaf litter. Transactions of the British Mycological Society 77(3): 457-473.

Kirk, P.M. 1984. Volutellaria laurina Tassi, an earlier name for Wiesneriomyces javanicus Koorders. Transactions of the British Mycological Society 82(4): 748-749.

Kuthubutheen, A.J. \& Nawawi, A. 1988. A new species of Wiesneriomyces (Hyphomycetes) from submerged decaying leaves. Transactions of the British Mycological Society 90(4): 619-625.

Lunghini, D. \& Quadraccia, L. 1990. Contributo alla conscenza degli ifomiceti demaziacei della Tenuta Presidenzialle di Castelporziano (Micoflora del Lazio III). Accademia Nazionale dei Lincei 264: 121 132.

Maniotis, J. \& Strain, J.W. 1968. Wiesneriomyces javanicus from Panamanian soil. Mycologia 60: 203-208. 
Matsushima, T. 1980. Saprophytic microfungi from Taiwan. Part I Hyphomycetes. Matsushima Mycological Memoirs 1: 1-82.

Matsushima, T. 1989. Matsushima Mycological Memoirs 6: 1-100.

Matsushima, T. 1993. Matsushima Mycological Memoirs 7: 1-75+131 plates.

Matsushima, T. 1995. Matsushima Mycological Memoirs 8: $1-54+120$ plates.

Mouchacca, J. 1990. Champignons de Nouvelle-Calédonie II. Quelques dématiées intéressantes de litière forestière. Nova Hedwigia 51: 459-468.

Pfenning, L. 1993. Mikroskopische Bodenpilze des ostamazonischen Regenwaldes (Brasilien). Tübingen. Universität Tübingen. Tese de Doutorado.

Pirozynski, K.A. 1972. Microfungi of Tanzania. Mycological Papers 129: 1-64.

Pirozynski, K.A. \& Hodges Jr., C.S. 1973. New Hyphomycetes from South Carolina. Canadian Journal of Botany 51: 157-173.

Rao, V. \& Hoog, G. S. 1986. New or critical Hyphomycetes from India. Studies in Mycology 28: 1-84.

Samuels, G.J. \& Dumont, K.P. 1982. The genus Nectria in Panama. Caldasia 13(63): 379-423.

Schol-Schwarz, M.B. 1959. The genus Epicoccum Link. Transactions of the British Mycological Society 42: 149-173.

Seifert, K.A. 1985. A monograph of Stilbella and some allied Hyphomycetes. Studies in Mycology 27: 1-135.

Seifert, K.A. \& Okada, G. 1990. Taxonomic implication of conidiomatal anatomy in synnematous Hyphomycetes. Studies in Mycology 32:29-40.

Sutton, B.C. \& Cole, G.T. 1983. Thozetella (Hyphomycetes): an exercise in diversity. Transactions of the British Mycological Society 81(1): 97-107.

Trappe, J.M. \& Schenck, N.C. 1982. Taxonomy of the fungi forming endomycorrhizae. Pp 1-9. In N.C. Schenck (Ed.). Methods and principles of mycorrhizae research. St. Paul. The American Phytopathological Society. 